\title{
THE KATO DECOMPOSITION OF QUASI-FREDHOLM RELATIONS
}

\author{
J.-Ph. Labrousse, A. Sandovici, H. S. V. DE Snoo \\ AND H. WINKLER
}

\begin{abstract}
Quasi-Fredholm relations of degree $d \in \mathbb{N}$ in Hilbert spaces are defined in terms of conditions on their ranges and kernels. They are completely characterized in terms of an algebraic decomposition with a quasi-Fredholm relation of degree 0 and a nilpotent operator of degree $d$. The adjoint of a quasi-Fredholm relation of degree $d \in \mathbb{N}$ is shown to be quasi-Fredholm relation of degree $d \in \mathbb{N}$. The class of quasi-Fredholm relations contains the semi-Fredholm relations. Earlier results for quasi-Fredholm operators and semi-Fredholm operators are included.
\end{abstract}

Mathematics subject classification (2000): Primary 47A57, 47B25; Secondary 47A55, 47B65. Keywords and phrases: Quasi-Fredholm relation, semi-Fredholm relation, Kato decomposition.

\section{REFERENCES}

[1] R. W. Cross, Multivalued linear operators, Marcel Dekker, New York, 1998.

[2] A. Dijksma And H. S. V. DE Snoo, Symmetric and selfadjoint relations in Krĕn spaces I, Ann. Acad. Sci. Fenn. Ser. A I Math., 12 (1987), 199-216.

[3] P. A. Fillmore and J. P. Williams, On operator ranges, Adv. Math., 7 (1971), 254-281.

[4] I. C. Gohberg AND M. G. KREǏn, The basic propositions on defect numbers, root numbers and indices of linear operators, Uspekhi Mat. Nauk., 12 (1957), 43-118 (Russian) [English translation: Transl. Amer. Math. Soc. (2), 13 (1960), 185-264].

[5] S. Hassi, Z. Sebestyén, H. S. V. DE SNOo, AND F. H. SZAFraniec, A canonical decomposition for linear operators and linear relations, Acta Math. Hungar., 115 (2007), 281-307.

[6] S. Hassi, H. S. V. DE Snoo, And F. H. SzAFraniec, Componentwise and canonical decompositions of linear relations, Dissertationes Mathematicae, 465 (2009), 59 pp.

[7] T. Kato, Perturbation theory for nullity, deficiency, and other quantities of linear operators, J. d'Anal. Math., 6 (1958), 261-322.

[8] T. Kato, Perturbation theory for linear operators, Springer-Verlag, Berlin, 1980.

[9] J.-PH. LABRousse, Les opérateurs quasi Fredholm: une généralisation des opérateurs semi Fredholm, Rend. Circ. Mat. Palermo (2), 29 (1980), 161-258.

[10] J.-PH. Labrousse, Idempotent linear relations, in Spectral Theory and Its Applications, Theta, 2003, 129-149.

[11] J.-Ph. Labrousse, A. Sandovici, H. S. V. DE Snoo, and H. Winkler, Quasi-Fredholm relations in Hilbert spaces, Universitatea din Bacau Studii si Cercetari Stiintifice, Ser. Mat., 16 (2006), 93-106

[12] M. Мвектha, Sur l'unicité de la decomposition de Kato generaliseé, Acta Sci. Math. (Szeged), 54 (1990), 367-377.

[13] Y. MeZroui, Le complété des opérateurs fermés à domaine dense pour la métrique du gap, J. Operator Theory, 41 (1999), 69-92.

[14] V. MÜLLER, On the Kato decomposition of quasi-Fredholm operators and B-Fredholm operators, Proc. Workshop Geometry in Functional Analysis, Erwin Schrödinger Institute, Wien, 2000.

[15] V. Müller And M. Mbektha, On the axiomatic theory of spectrum, Studia Math., 119 (1996), $129-147$.

[16] V. RAKoČEvić, Semi-Browder operators and perturbations, Studia Math., 122 (1997), 131-137. 
[17] A. SANDovici, H. S. V. DE SNOO, AND H. WinkLER, The structure of linear relations in Euclidean spaces, Lin. Alg. Appl., 397 (2005), 141-169.

[18] A. Sandovici, H. S. V. DE SNOo, AND H. WinkLer, Ascent, descent, nullity, defect, and related notions for linear relations in linear spaces, Lin. Alg. Appl., 423 (2007), 456-497. 